\title{
Technology Readiness Levels For Advanced Nuclear Fuels and Materials Development
}

Jon Carmack

January 2014

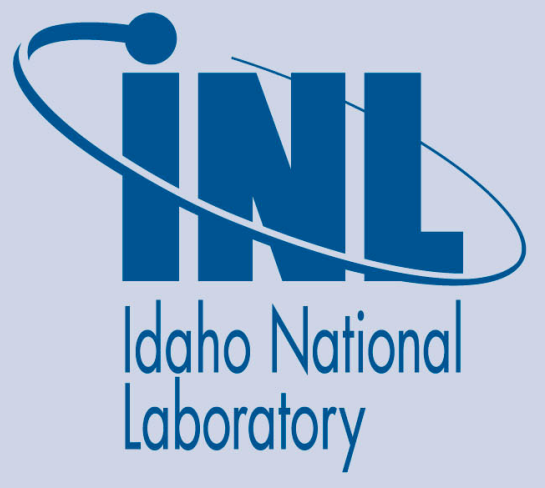

The INL is a U.S. Department of Energy National Laboratory operated by Battelle Energy Alliance 
INL/EXT-14-31243

FCRD-FUEL-2014-000577

\title{
Technology Readiness Levels For Advanced Nuclear Fuels and Materials Development
}

\author{
Jon Carmack
}

January 2014

\section{Idaho National Laboratory \\ Fuel Cycle Research \& Development Idaho Falls, Idaho 83415}

http://www.inl.gov

Prepared for the

U.S. Department of Energy

Office of Nuclear Energy

Under DOE Idaho Operations Office

Contract DE-AC07-05ID14517 


\section{DISCLAIMER}

This information was prepared as an account of work sponsored by an agency of the U.S. Government. Neither the U.S. Government nor any agency thereof, nor any of their employees, makes any warranty, expressed or implied, or assumes any legal liability or responsibility for the accuracy, completeness, or usefulness, of any information, apparatus, product, or process disclosed, or represents that its use would not infringe privately owned rights. References herein to any specific commercial product, process, or service by trade name, trade mark, manufacturer, or otherwise, does not necessarily constitute or imply its endorsement, recommendation, or favoring by the U.S. Government or any agency thereof. The views and opinions of authors expressed herein do not necessarily state or reflect those of the U.S. Government or any agency thereof. 


\section{Submitted by:}

AFC Systems Engineering

\begin{tabular}{cc} 
hori Draase & $1 / 31 / 14$ \\
\hline Lori Braase & Date
\end{tabular}

Approved by:

National Technical Director

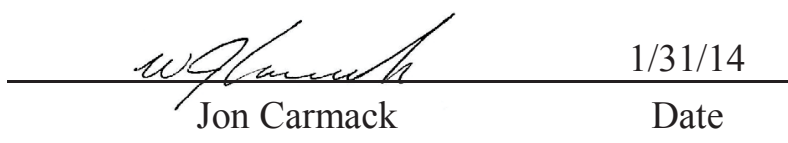

Approved by:

Federal R\&D Manager

\begin{tabular}{cc} 
Rosi Draase for Frank Goldner & 2/18/14 \\
\hline Frank Goldner & Date
\end{tabular}


Intentionally Blank 


\section{EXECUTIVE SUMMARY}

The Technology Readiness Level (TRL) process is used to quantitatively assess the maturity of a given technology. The TRL process has been developed and successfully used by the Department of Defense (DOD) for development and deployment of new technology and systems for defense applications. In addition, NASA has also successfully used the TRL process to develop and deploy new systems for space applications.

Advanced nuclear fuels and materials development is a critical technology needed for closing the nuclear fuel cycle. Because the deployment of a new nuclear fuel forms requires a lengthy and expensive research, development, and demonstration program, applying the TRL concept to the advanced fuel development program is very useful as a management and tracking tool. This report provides definition of the technology readiness level assessment process as defined for use in assessing nuclear fuel technology development for the Advanced Fuel Campaign (AFC). 


\section{CONTENTS}

EXECUTIVE SUMMARY vi

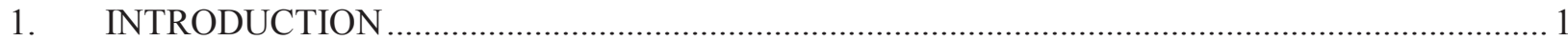

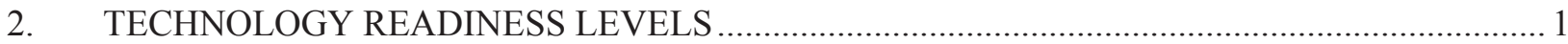

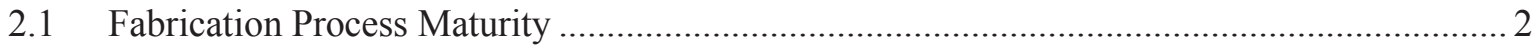

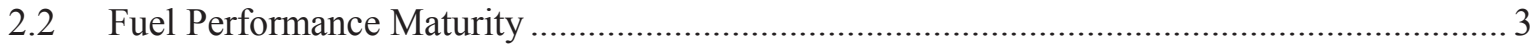

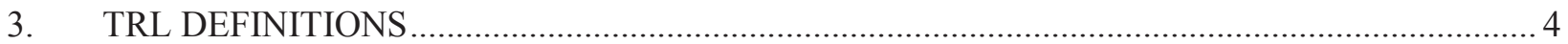

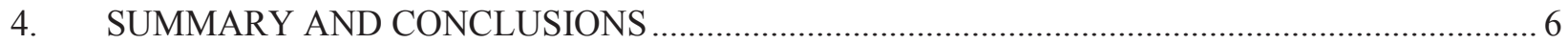

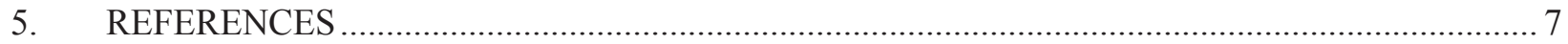

\section{FIGURES}

Figure 1. Summary of TRL Evaluation Elements, Attributes, and Bins...................................................2

Figure 2. High Level TRL Completion Criteria for Nuclear Fuels and Materials..................................... 4

Figure 3. TRL Binning for Fabrication Process Maturity....................................................................... 5

Figure 4. TRL Binning for Irradiation Performance Maturity.............................................................. 5

Figure 5. Summary of TRL Definitions for Advanced Nuclear Fuels Development. .............................. 6 
Intentionally Blank 


\section{TECHNOLOGY READINESS LEVELS FOR ADVANCED NUCLEAR FUELS AND MATERIALS DEVELOPMENT}

\section{INTRODUCTION}

In order to provide a quantitative assessment for the maturity of a given system relative to its full-scale deployment, a technology readiness level (TRL) process was developed and used by the Department of Defense (DoD) ${ }^{1}$. Subsequently, the National Aeronautics and Space Administration (NASA) also successfully used the TRL process to develop and deploy new systems.

Advanced nuclear fuels research is a critical part of the Fuel Cycle Research and Development (FCRD) program aimed at developing advanced technologies for closing the nuclear fuel cycle. TRLs provide a framework for identification and prioritization of the needed activities associated with nuclear fuels and materials development.

\section{TECHNOLOGY READINESS LEVELS}

Many technologies, including reactor fuels, are developed through a sequence of activities, often iteratively. To measure and indicate technical progress with a fuel concept or design, a technical readiness level (TRL) scale can be applied to nuclear fuels and materials. ${ }^{2}$

There are two elements used to evaluate the maturity of a new fuel type in terms of readiness for deployment:

A. Fabrication Process Maturity, which measures how well the fabrication process is understood and validated

B. Fuel Performance Maturity, which measures how well the in-pile performance of the fuel is understood and validated.

A TRL definition that provides a balance between these two elements is essential. Having a very mature fabrication process tested at very large scales for fuels with large uncertainties in its performance certainly does not make sense. On the other hand, collecting a lot of performance data through large-scale testing without a mature definition of the fabrication process is equally unbalanced. As shown in Figure 1, for each element, there are two attributes identified for assessing the TRL levels. For each attribute, there are distinct bins against which the state-of-knowledge can be compared. The TRL Evaluation Criteria are discussed in detail in the following subsection. 


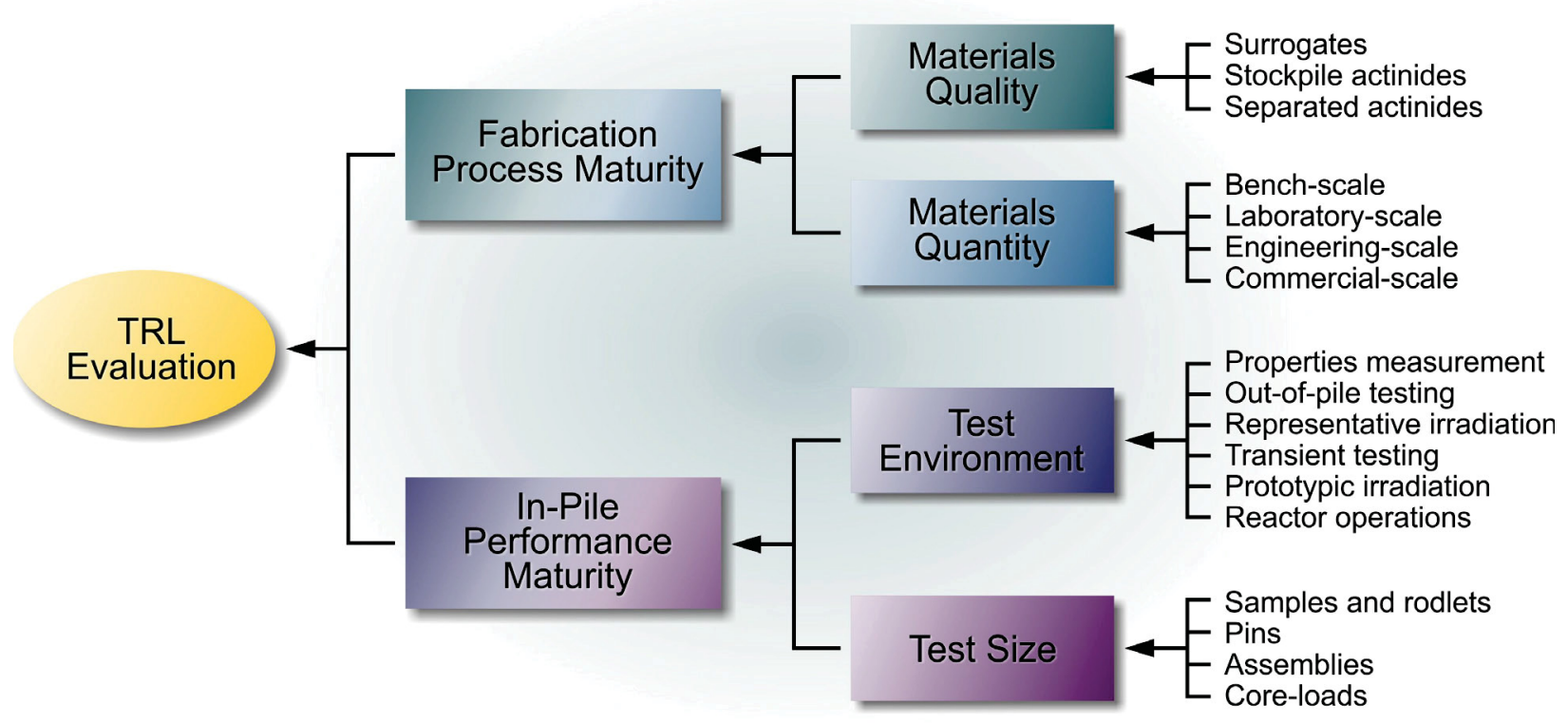

Figure 1. Summary of TRL Evaluation Elements, Attributes, and Bins.

\subsection{Fabrication Process Maturity}

To gauge the maturity of the fabrication process, there are two important attributes that must be considered:

1. Quality of Materials Used For Fabrication Process Development and Testing. This attribute is broken into three bins to gauge the TRL.

- $\quad$ Surrogate Materials - These are typically non-radioactive or less-radioactive materials with properties similar to the actual actinides. The selection of a surrogate depends on the specific phenomenon of interest and the properties that are important to predict or duplicate the phenomenon as closely as possible without using actual actinide materials.

- $\quad$ Representative Materials from Stockpile - These are individually separated actinide elements that must be blended together for use in fuel fabrication experiments. Quite often, the physical form of these materials is not prototypic of what would be used as feedstock for fuel fabrication; thus, a non-prototypic conditioning step would be necessary. Also, the isotopic vectors for stockpile actinides are typically different than those obtained from the separation process using commercial spent nuclear fuel. Those differences must be accounted for in the fabrication testing as well.

- Representative Materials from Recycling Process - Ultimately, the fabrication process must be optimized using actinides recovered from the separations processes, co-precipitated through a prototypic process, and conditioned to be used as feedstock. This phase of the development process requires a coordinated effort between the recycling and fuel refabrication activities.

2. Quantity of Materials Used for Fabrication Process Development and Testing. This parameter is broken into four categories to gauge the TRL. The quantity can be measured as batch size and/or throughput rate.

- $\quad$ Bench-Scale Fabrication - Dealing with gram quantities up to $100 \mathrm{~g}$ batch sizes (multiple pellets/slugs $1 \mathrm{~g}-1 \mathrm{~kg}$ per year). 
- Laboratory-Scale Fabrication - Dealing with up to $1 \mathrm{~kg}$ quantity batch sizes with an equivalent throughput rate on the order of $10 \mathrm{~kg}$ TRU /year (multiple pins/year).

- Engineering-Scale Fabrication - Dealing with 1-10 kg quantity batch sizes with an equivalent throughput rate on the order of $100 \mathrm{~kg}$ TRU /year (a few assemblies/year).

- $\quad$ Commercial-Scale Fabrication - Dealing with batch sizes that are the same order of magnitude as the engineering-scale batch sizes but at a throughput rate on the order of tons of TRU/year (a few hundred assemblies per year - core loads).

\subsection{Fuel Performance Maturity}

To gauge the maturity of fuel performance, there are two important parameters that must be considered:

1. Test Environment to Determine Performance Parameters. This parameter is broken into six categories to gauge the TRL.

- Fundamental Property Measurements - This category includes measurements of basic mechanical, thermal, and chemical properties of samples that are fabricated through a representative process and that conform to defined specifications.

- $\quad$ Out-of-Pile Testing - This category includes experiments conducted without using reactor/neutron irradiations but that provide insight into the behavior of fuel and cladding. Examples of such tests include diffusion-couple experiments, microstructure evolution tests, ion-beam irradiation tests, thermal segregation experiments, oxidation and reaction kinetics, etc.

- In-Pile Testing in Representative Spectrum - These are neutron irradiation experiments with fission where the spectrum and/or flux levels and/or thermal boundary conditions are not prototypic of the intended reactor application. Therefore, fuel design and enrichment levels may have to be adjusted to accommodate the non-prototypic nature of the irradiation environment. A good example is testing nuclear fuels using a thermal test reactor with or without partial filtering of thermal neutrons. Completion of the irradiation experiments implies that the associated postirradiation examination (PIE) is performed.

- $\quad$ Transient Testing - This category includes transient tests to mimic fuel behavior during design basis accidents. The failure threshold determination also is covered under this category. Full size or partial size pins both before and after irradiation can be used in these tests. Irradiated pins may be those tested in representative or prototypic spectrum. Completion of the irradiation experiments implies that the associated PIE is performed.

- In-Pile Testing in Prototypic Spectrum - These irradiations are typically conducted in a reactor where flux, spectrum, and thermal effects are very similar to the actual reactor conditions for which the fuel is being licensed. Completion of the irradiation experiments implies that the associated PIE is performed.

- $\quad$ Reactor Operations - At this level, large quantities of licensed fuel are used in actual reactor operations. Postirradiation examination of selected pins may be performed to verify performance.

2. Size of Test Campaigns to Assess Performance Parameters. This parameter is broken into four categories to gauge the TRL. In addition to size, the test geometry and the cladding used in the testing campaigns are also of importance for these categories.

- $\quad$ Samples \& Rodlets - These are samples (pellets, short slugs, etc.) tested in the form of rodlets (on the order of $10 \mathrm{~cm}$ fuel height). The testing may or may not include prototypic cladding and prototypic cladding-coolant interactions. These tests are typically designed to investigate specific issues/phenomena. 
- $\quad \underline{\text { Pins }}$ - These tests include close to full-length pins with representative fuel heights and plenum volumes. Prototypic cladding materials are typically used in these tests.

- $\quad$ Assemblies - These tests contain assemblies of prototypic design. Lead test assemblies (LTAs) as well as a limited number of assemblies used for partial core conversion are included in this category. Prototypic cladding and assembly materials are used in these tests.

- $\quad$ Full-Core Assemblies - At this level, the irradiation is no longer a test program but an operations program where the statistical and long-term reliability related issues are quantified for the fuel type and design of interest.

\section{TRL DEFINITIONS}

Full maturity requires long-term routine operations of commercial fabrication plant(s) supplying fuels to operating reactors. At this point, adequate statistical data are available for fuel fabrication and performance, and the system is optimized within the constraints of the performance envelope. This level of maturity is assigned a numerical score of 9 for the corresponding TRL.

At the other end of the spectrum, when a new concept is proposed and it is shown that the concept is viable based on first principles assessment, a numerical score of 1 is assigned for the corresponding TRL.

The intermediate steps are defined based on the logical progression of the research and development towards demonstration and deployment. The criteria in Figure 2 determine the completion of the corresponding TRL level.

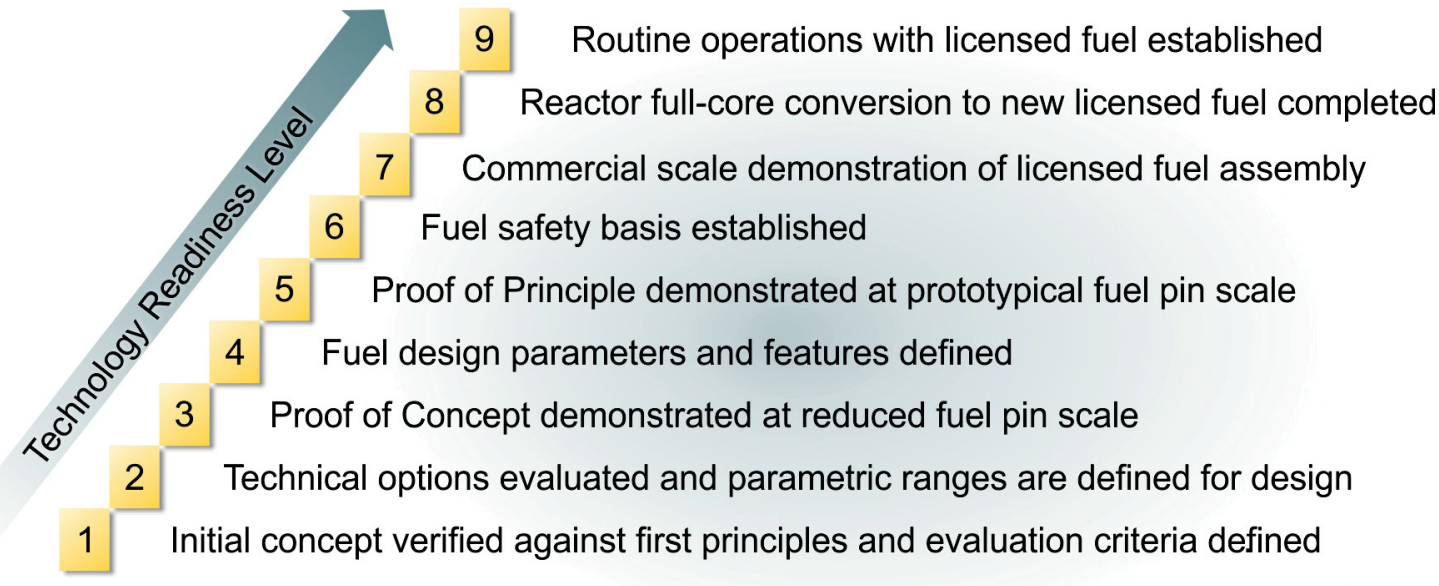

Criteria

Figure 2. High Level TRL Completion Criteria for Nuclear Fuels and Materials

The process of evaluating the TRL is based on binning the state-of-knowledge for each attribute. Then, given the criteria, various activities required to achieve these goals are identified as a function of the technical elements, attributes, and bins (discussed in Section 2). The resulting TRLs are shown in Figure 3 and Figure 4, for the fabrication and performance elements, respectively. The technology must be developed to the point that fabrication and performance maturity have been achieved to move to the next TRL level. 


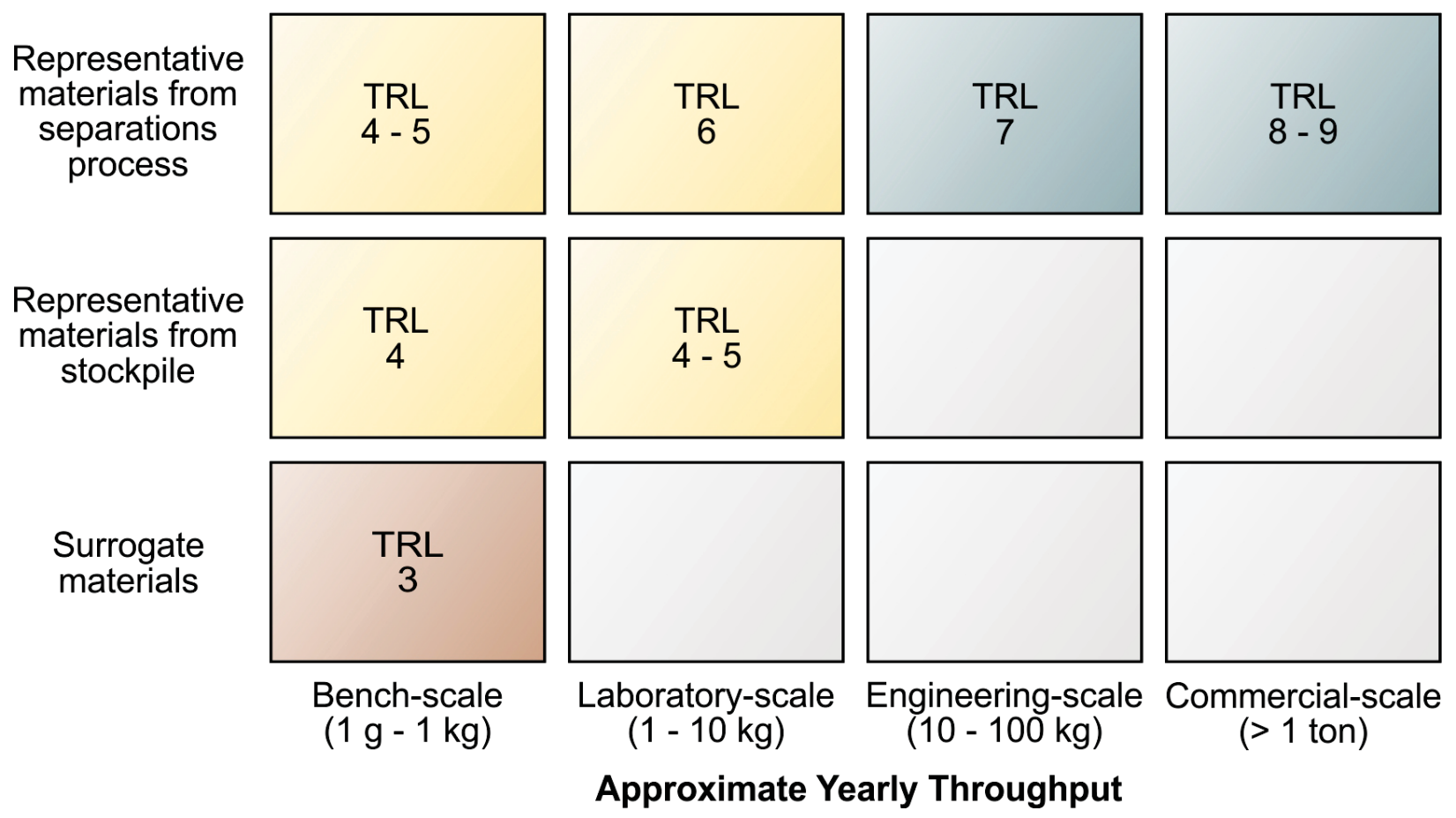

Figure 3. TRL Binning for Fabrication Process Maturity.

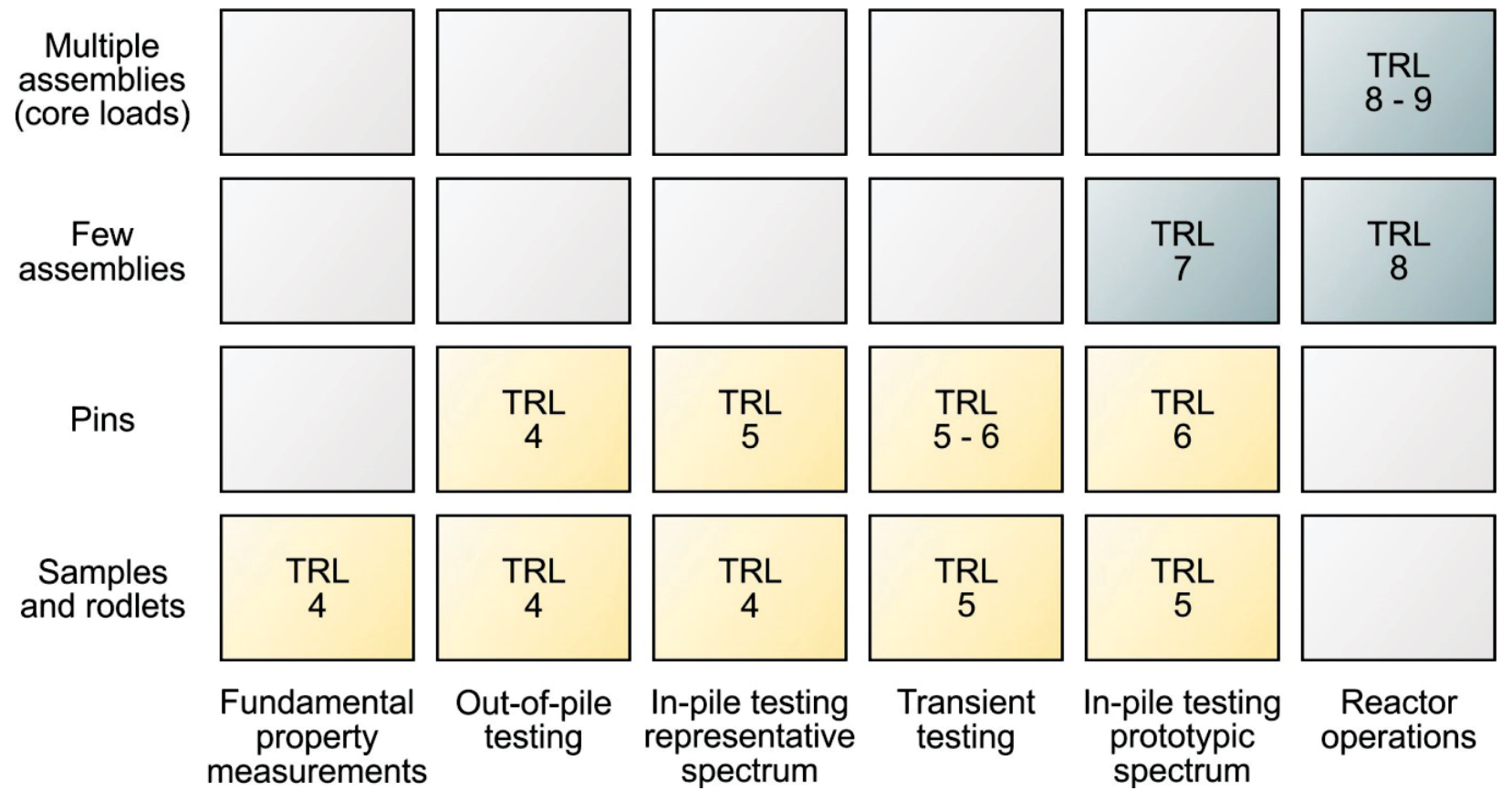

Figure 4. TRL Binning for Irradiation Performance Maturity. 
Figure 5 summarizes the criteria and the activities needed to achieve the criteria for various TRL levels specific to advanced fuel development. The definition of the TRL levels is based on a logical progression of the work, while considering fabrication and performance testing activities in tandem. All the activities in a given level must be completed before advancing to the next level.

\begin{tabular}{|c|c|c|c|}
\hline \multicolumn{3}{|c|}{ TRL Function } & \multirow[b]{3}{*}{ LWR Accident Tolerant Fuels } \\
\hline 1 & \multirow{3}{*}{$\begin{array}{l}\text { 艹0 } \\
0 \\
0 \\
0 \\
0 \\
0 \\
\frac{1}{0} \\
\frac{1}{0} \\
0 \\
0 \\
0\end{array}$} & $\begin{array}{l}\text { A new concept is proposed. Technical options for the concept are } \\
\text { identified and relevant literature data reviewed. Criteria developed. }\end{array}$ & \\
\hline 2 & & $\begin{array}{l}\text { Technical options are ranked. Performance range and fabrication } \\
\text { process parametric ranges defined based on analyses. }\end{array}$ & \\
\hline 3 & & $\begin{array}{l}\text { Concepts are verified through laboratory-scale experiments and } \\
\text { characterization. Fabrication process verified using surrogates. }\end{array}$ & \multirow{2}{*}{$\begin{array}{l}\text { Transmutation Fuel } \\
\text { TRU-metal, TRU-oxide } \\
\text { (roughly same TRL) } \\
\text { Metal experience: mostly U.S. } \\
\text { Oxide experience: mostly } \\
\text { International (France and Japan) }\end{array}$} \\
\hline 4 & \multirow{3}{*}{$\begin{array}{l}\frac{0}{0} \\
\frac{0}{5} \\
\frac{0}{0} \\
\frac{1}{0} \\
\frac{1}{0} \\
\frac{1}{0} \\
0\end{array}$} & $\begin{array}{l}\text { Fabrication of samples using stockpile materials at bench-scale. } \\
\text { Irradiation testing of small-samples (rodlets) in relevant } \\
\text { environment. Design parameters and features established. Basic } \\
\text { properties compiled. }\end{array}$ & \\
\hline 5 & & $\begin{array}{l}\text { Fabrication of pins using prototypic feedstock materials at } \\
\text { laboratory-scale. Pin-scale irradiation testing at relevant } \\
\text { environment. Primary performance parameters with representative } \\
\text { compositions under normal operating conditions quantified. Fuel } \\
\text { behavior models developed for use in fuel performance code(s). }\end{array}$ & \multirow{2}{*}{$\begin{array}{l}\text { Fast Reactor Metallic } \\
\text { U-Pu-Zr } \\
\text { - Not formally licensed for a full } \\
\text { core load } \\
\text { - Not used in industrial-scale }\end{array}$} \\
\hline 6 & & $\begin{array}{l}\text { Fabrication of pins using prototypic feedstock materials at } \\
\text { laboratory-scale and using prototypic fabrication processes. Pin- } \\
\text { scale irradiation testing at relevant and prototypic environment } \\
\text { (steady-state and transient testing). Predictive fuel performance } \\
\text { code(s) and safety basis established. }\end{array}$ & \\
\hline 7 & \multirow{3}{*}{$\begin{array}{l}0 \\
0 \\
\frac{0}{0} \\
\frac{0}{0} \\
0 \\
\frac{0}{0} \\
0 \\
\frac{1}{0} \\
\frac{1}{0} \\
\frac{1}{0} \\
\text { 인 } \\
\end{array}$} & $\begin{array}{l}\text { Fabrication of test assemblies using prototypic feedstock materials } \\
\text { at engineering-scale and using prototypic fabrication processes. } \\
\text { Assembly-scale irradiation testing in prototypic environment. } \\
\text { Predictive fuel performance code(s) validated. Safety basis } \\
\text { established for full-core operations. }\end{array}$ & \multirow{2}{*}{$\begin{array}{l}\text { Fast Reactor Metallic (U-Zr), } \\
\text { Oxide (U, Pu) } \\
\text { - Licensed for reactor operations } \\
\text { - Successful mission operations } \\
\text { - Operational database wider for } \\
\text { MOX, especially considering } \\
\text { International experience }\end{array}$} \\
\hline 8 & & $\begin{array}{l}\text { Fabrication of a few core-loads of fuel and operation of a prototype } \\
\text { reactor with such fuel. }\end{array}$ & \\
\hline 9 & & Routine commercial-scale operations. Multiple reactors ope & LVVN $u_{2}$ \\
\hline
\end{tabular}

Figure 5. Summary of TRL Definitions for Advanced Nuclear Fuels Development.

\section{SUMMARY AND CONCLUSIONS}

The TRL concept is used as a program management tool and is not meant as an absolute quantitative measure of maturity. There is naturally a level of subjectivity in defining and in evaluating the TRLs. Nonetheless, with the granularity provided in the methodology outlined in this report, the technical maturity evaluations will provide a semi-quantitative, relative measure specifically for the advanced fuel technology and in general to any new fuel concept.

Finally, it is important to recognize the difference between the TRL evaluations and technical risk. The TRL only provides a relative measure of where the technology maturity is compared to the end objective of large-scale deployment. A low TRL does not necessarily mean a high technical risk. Technical risk depends on many factors (e.g., the complexity of the remaining work, the availability of the needed resources, schedule constraints) and must be evaluated independently. 


\section{REFERENCES}

1. Department of Defense, "Mandatory Procedures for Major Defense Acquisition Programs (MDAPS) and Major Automated Information System (MAIS) Acquisition Programs," April 5, 2002, DoD 5000.2-R.

2. D.C. Crawford, D.L. Porter, S.L. Hayes, M.K. Meyer, D.A. Petti, K.O. Pasamehmetoglu, "An approach to fuel development and qualification," Journal of Nuclear Materials, 371, (2007) 232242. 